\title{
Critical analysis of necking and fracture limit strains and forming forces in single-point incremental forming
}

\author{
Gabriel Centeno $^{\mathrm{a}, *}$, Isabel Bagudanch ${ }^{\mathrm{b}}$, A.J. Martínez-Donaire ${ }^{\mathrm{a}}$, M.L. García-Romeu ${ }^{\mathrm{b}}$, C. Vallellano ${ }^{\mathrm{a}}$ \\ ${ }^{a}$ Department of Mechanical and Manufacturing Engineering, University of Seville, Camino de los Descubrimientos s/n, 41092 Sevilla, Spain \\ ${ }^{\mathrm{b}}$ Department of Mechanical Engineering and Industrial Construction, University of Girona, C/Maria Aurèlia Capmany, 61.17071 Girona, Spain
}

\section{A R T I C L E I N F O}

\section{Article history:}

Received 28 March 2014

Accepted 29 May 2014

Available online 6 June 2014

\section{Keywords:}

Single-point incremental forming

Forming force

Formability limits

Spifability

Bending effect

\begin{abstract}
A B S T R A C T
Single-Point Incremental Forming (SPIF) is an emerging manufacturing process especially suitable to produce small batches of metal parts. Moreover, the enhanced formability of metal sheets deformed by SPIF makes this technology useful to those industrial applications requiring high deformation levels. In this sense, the precise setting of limit strains in SPIF in relation to the conventional formability limits of the material, as well as the influence of the process parameters on these strains, are essential variables to understand how and how much can be deformed the metal sheets in real production. On the other hand, the forming force in SPIF is an essential variable, especially for the design of dedicated equipment or for the safe use of adapted machinery. This paper revisits failure in SPIF by means of an experimental analysis of the influence of process parameters, such as the tool diameter, the spindle speed and the step down, on the formability in SPIF (spifability) of AISI 304 metal sheets, studied in the light of circle grid analysis. The work also involves the independent determination of conventional formability limits by necking and fracture under laboratory conditions by using stretching tests (Nakazima tests), in conjunction with stretch-bending tests performed in order to quantify the influence of the bending induced by the tool radius. Failure strains are experimentally obtained and compared in stretch-bending and SPIF tests, being the failure mode discussed in each case. Finally, the axial forming force evolution was recorded with the aim of analyzing the range of process parameters that would guarantee the safely utilization of the non-dedicated process equipment.
\end{abstract}

๑) 2014 Elsevier Ltd. All rights reserved.

\section{Introduction}

Incremental sheet forming is an innovative process that fulfils the current requirements for flexible, sustainable and economic manufacturing technologies viable for small and medium-sized batches, not being necessary the use of expensive dedicated machines or equipments. The paper by Jeswiet et al. [1] describes exhaustively the genesis, development and applications of this technology as well as its basic components, focusing specially on the manufacture of parts by asymmetric Single-Point Incremental Forming (SPIF).

Single-point incremental forming is the simplest manufacturing process among those based on incremental forming of a metal sheet. As shown in Fig. 1, the SPIF process consists on an hemispherical end forming tool driven by a Computer Numerical Control (CNC) machine that follows progressively a pre-establish trajectory, deforming a peripherally clamped sheet blank into a final component, without the use of a forming die during the process.

\footnotetext{
* Corresponding author. Tel.: +34 954485965 .

E-mail address: gaceba@us.es (G. Centeno).
}

In general, high ductility materials formed by conventional sheet metal forming processes usually start failing with the onset of strain localization along a narrow stripe. The material deforms continuously within this neck under an instable deformation process, following approximately a near plane strain state, until the ductile fracture takes place. On the contrary, assuming the unified view on formability limits and development of fracture proposed in [2], metal sheets deformed by SPIF (or any other incremental forming process) under a certain range of process parameters suffer a stable straining around plane strain conditions that seems to lead directly with ductile fracture. Both failure situations are commonly analysed within the principal strain space by means of the forming limit diagrams (FLD). The FLD shows the combinations of strains at the onset of local necking, FLD at necking or Forming Limit Curve (FLC), and at the beginning of ductile fracture, FLD at fracture or Fracture Forming Line (FFL). According to this, the Fig. 2 depicts the presumed straining evolution at the outer surface of the metal sheet until failure for a SPIF and a stretching process.

The keynote review paper by Emmens and Van den Boogaard [3] analyses the mechanisms that have been suggested to explain the stable plastic deformation above the FLC in incremental 


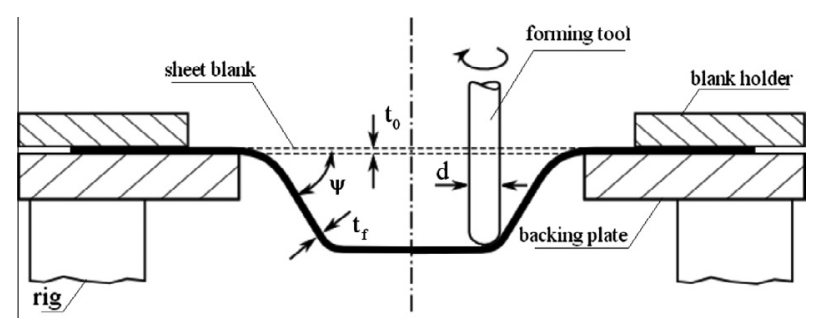

(a)

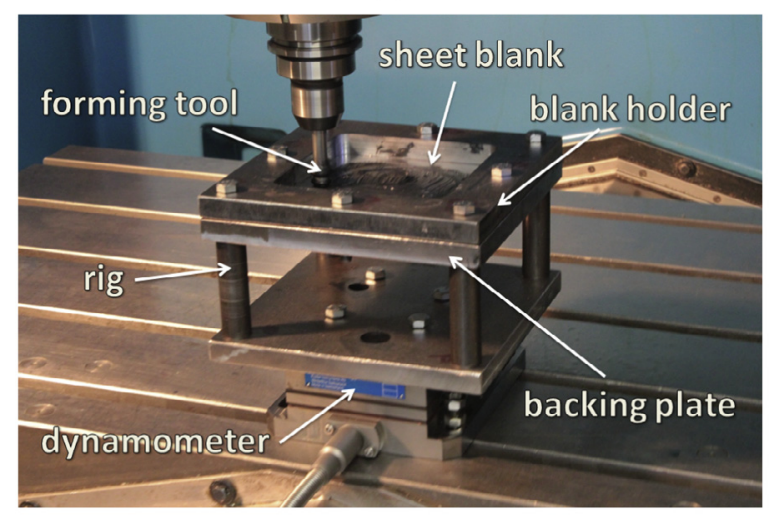

(b)

Fig. 1. (a) Schematic representation of SPIF and (b) experimental setup.

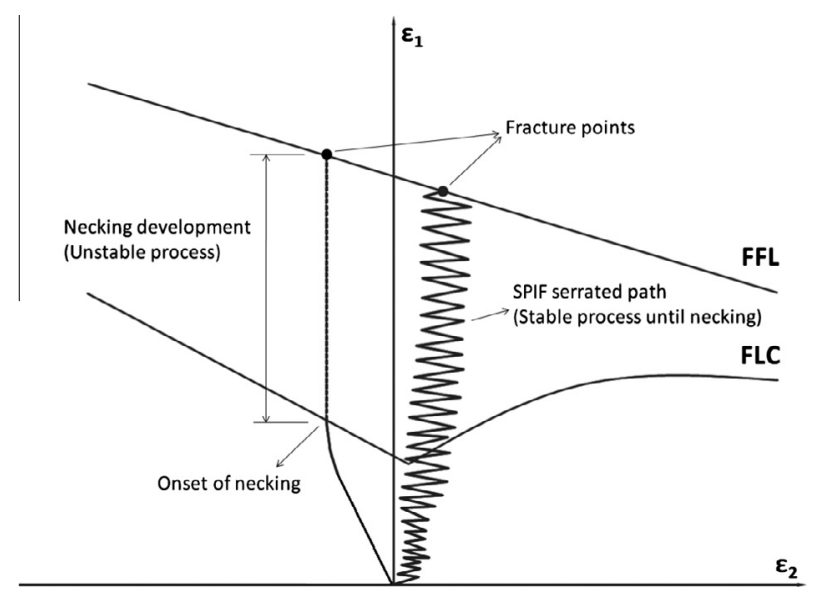

Fig. 2. Straining until failure of a metal sheet in stretching and SPIF, for a point located at the outer surface of the metal sheet.

forming. The mechanisms that have been claimed to explain the enhanced formability in SPIF are mainly: (1) the localized bending, (2) the through thickness shear generated by the tangential stresses due to the tool-sheet contact and (3) the triaxiality by mean of hydrostatic stresses. Other parameters such as the friction conditions and the cyclic straining due to the successive tool passes could also play a role. During the last years, there have been attempts not only (a) to quantify the weight of each of these mechanisms in the enhanced formability in SPIF [2,3], but also to (b) discern if spifability is either limited by a postponed necking or by ductile fracture without a previous necking [2]. On the one hand, Silva et al. [2] analysed the influence of the bending effect in SPIF by means of the $t_{0} / R$ ratio, initial sheet thickness to tool radius (as did the authors in [4]) concluding that bending is a dominant factor controlling the failure mechanism in SPIF. On the contrary, other authors such as Allwood and co-workers [5,6] or Eyckens et al. $[7,8]$ attribute the enhancement of formability in SPIF to the strain stabilization process due to the large amount of through-thickness shear. Likewise the influence of cyclic stretchbending in the increment of stability in incremental forming was also investigated by Emmens and Van den Boogaard [9].

Previous research works by the authors $[10,11]$ pointed out that the local evolution of the stress/strain across the sheet thickness is essential to explain the effect of bending in the enhanced formability of the metal sheet. In fact, depending on the severity of the strain gradient, two types of failures can be expected: (1) a necking-controlled failure, which takes place when the entire sheet thickness becomes plastically unstable for smooth or moderate through-thickness strain gradient; and (2) a fracture-controlled failure, which arises when necking cannot develop due to a severe strain gradient in the sheet thickness and the outer layers of the sheet fracture in the absence of necking. In this way, the former failure is mainly controlled by the evolution of the stress/strain gradient at the inner side of the sheet (i.e. punch-sheet contact side), and the latter one is governed by the evolution of the stress/strain gradient at the outer side of the sheet. This description explains successfully the beneficial bending effects in stretchbending operations, as it was also observed by Stoughton and Yoon [12]. These studies allow conclude that the failure mode above described clearly depends on the parameter defined as the $t_{0} / R$ ratio (initial sheet thickness to radius of the forming tool), for both stretch-bending operations [10-12] and for incremental sheet forming processes [2].

In addition, forming force estimation in SPIF is especially important in the case of using machinery adapted for the process like milling centers and robots [1]. It has been demonstrated that the predominant force in SPIF is developed in the axial direction of the tool while this, in general, is not the case in milling. As a consequence, an accurate estimation of the maximum axial force developed during the forming process is required in order to ensure the safe utilization of the non-dedicated CNC machinery. Aiming for quick estimations of the maximum force, several researchers have proposed analytical models intended for uniform wall angle (UWA) geometries formed with different materials, such as the empirical equation obtained by Aerens et al. [13]. This equation considers some of the most important process parameters: sheet thickness, tool diameter, step down and wall angle. However, it does not take into account the effect of the spindle speed, which it has been demonstrated to affect both the forming temperature and the formability as the tool speed increases [14]. Therefore, this parameter may also potentially affect the forming force. Another relevant works devoted to numerically predict the tool force occurring in SPIF were proposed by Eyckens et al. [15] and Henrard et al. [16], who concluded that force prediction requires an accurate modelling of the Through-Thickness Shear (TTS).

This paper contains a critical analysis on the experimental strain paths in SPIF and stretch-bending processes sustaining similar bending conditions. The development of those straining processes is evaluated until failure by using Digital Image Correlation (DIC) techniques as well as circle grid analysis. The results show that, although the localized bending induced by the forming tool through the above mentioned $t_{0} / R$ ratio plays a fundamental role in allowing stable plastic deformation above the FLC in SPIF, this is not the only parameter explaining this enhanced formability. On the other hand, the forming forces were recorded to determine the range of process parameters that ensure the safely utilization of the non-dedicated process equipment.

\section{Experimentation}

This section begins with the obtaining of the forming limits of the AISI 304 metal sheets by means of conventional Nakazima tests, followed by a series of stretch-bending tests carried out with 
a set of cylindrical punches. After that, the experimental plan of the SPIF tests carried out is presented. It must be pointed out that, for the whole plan of experiments comprising this experimental study, every single test was carried out at least on three specimens in order to provide statistical meaning to the results.

\subsection{Mechanical characterization and conventional forming limits}

The material used in this study is stainless steel AISI 304, supplied as sheets of $0.8 \mathrm{~mm}$ thickness. The mechanical properties of the metal sheets are summarized in Table 1.

As pointed out in a previous work of the authors [17], the plastic behaviour of the material fits a Swift's power law as follows:

$\bar{\sigma}=K\left(\varepsilon_{0}+\bar{\varepsilon}^{P}\right)^{n}$

The material characterization of the AISI 304 sheets $0.8 \mathrm{~mm}$ thickness, was carried out by means of a series of Nakazima tests (hemispherical punch of $\emptyset 100 \mathrm{~mm}$ ) using the three different specimen geometries shown in Fig. 3. The conventional forming limits represented by the FLC and the FFL were obtained. The Nakazima tests were performed in a universal sheet metal testing machine Erichsen 142-20 (see Fig. 3) under the testing conditions of the standard ISO 12004-2:2008 [18]. The punch velocity was set to $1 \mathrm{~mm} / \mathrm{s}$ and the lubricant at the interface punch-sheet was Vaseline + PTFE + Vaseline.

The optical deformation measurement system ARAMIS ${ }^{\circledR}$, based on digital image correlation technique, was used to evaluate the strain distributions at the outer surface of the tested sheets. A local methodology proposed by the authors $[19,20]$ for detecting the onset of localised necking was applied to the three strain paths

Table 1

Mechanical properties of the AISI 304 metal sheets.

\begin{tabular}{llllll}
\hline UTS $(\mathrm{MPa})$ & $\sigma_{\mathrm{y} 0.2}(\mathrm{MPa})$ & $E(\mathrm{GPa})$ & $K(\mathrm{GPa})$ & $n$ & $\varepsilon_{0}$ \\
\hline 669 & 503 & 207 & 1.55 & 0.594 & 0.055 \\
\hline
\end{tabular}

considered (uniaxial strain, near plane strain and biaxial strain state) in order to determine if the material presented either a necking-controlled failure or a fracture-controlled failure, i.e. the metal sheets failed directly by fracture in absence of a distinctive necking. Fig. 4a shows the time evolution of the major strain $\left(\varepsilon_{1}\right)$ for a series of points distributed from the fracture outward along a section perpendicular to the failure zone in a Nakazima test close to plane strain conditions. As it can be seen, the strain evolution at the different points practically superimposed during most of the test due to the small strain gradient induced by the gentile punch radius. However, in the final stages, the curves separated from each other, showing two clearly differentiated behaviours. Some points increased their strain level very quickly until fracture, while other points ceased to strain and even underwent some elastic unloading immediately before failure. This means that the strain was concentrated within a narrow band in which the sheet finally ruptured. Fig. $4 \mathrm{~b}$ depicts the principal strain path at the point closest to the failure zone in a $\varepsilon_{1}-\varepsilon_{2}$ diagram in both a Nakazima test and stretch-bending test using $\Phi 20 \mathrm{~mm}$ punch. Focusing on the Nakazima test evolution, it can be seen in the last stages a change in the slope of the strain path towards a local plane strain condition, as consequence of the onset of plastic instability. These behaviours, which are characteristic in a necking-controlled failure, were observed in all of the Nakazima tests.

The conventional FLD for the selected material under Nakazima stretching tests is depicted in Fig. 5. As explained above, the FLD includes the necking limit strains on the outer surface represented by the FLC (Forming Limit Curve) as well as the fracture limit strains, determined by a similar methodology as the one presented in [21] and used in many other studies such as [2,22,23], based on the work of Atkins [24,25]. On the one hand, the FLC was built following the entire methodology of the ISO standard [18] mentioned above, and the methodology proposed by the authors [20], being both results almost identical. The procedure for constructing the FFL starts by measuring the thickness at fracture at several places along the crack in order to obtain the average thickness strain. The average thickness strain was evaluated at both sides of the crack

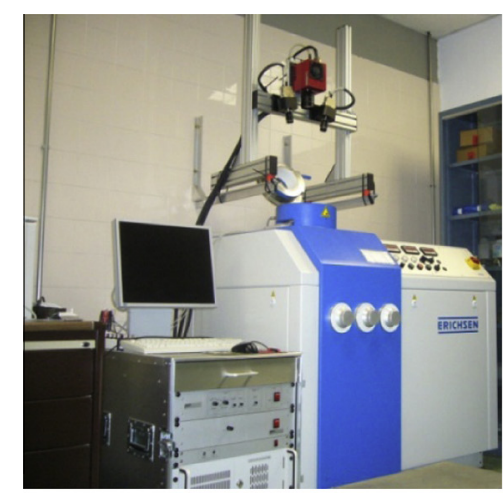

(a)

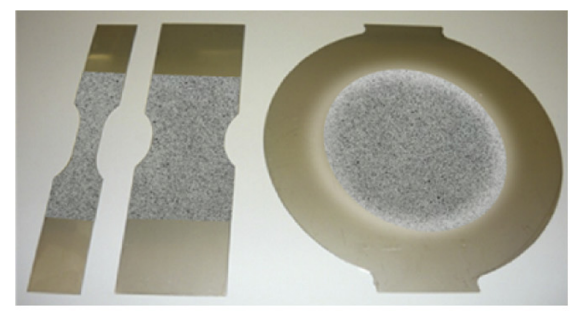

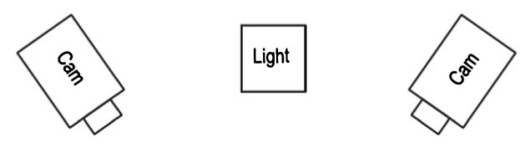

Sheet

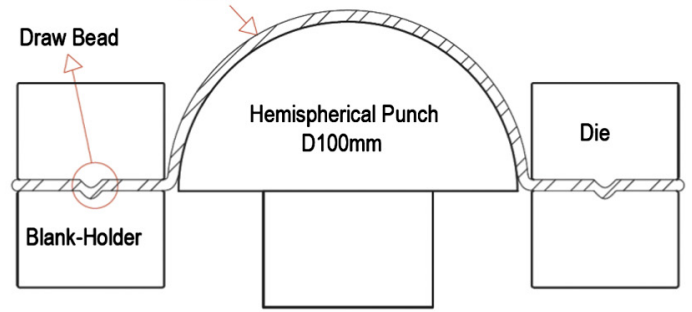

(b)

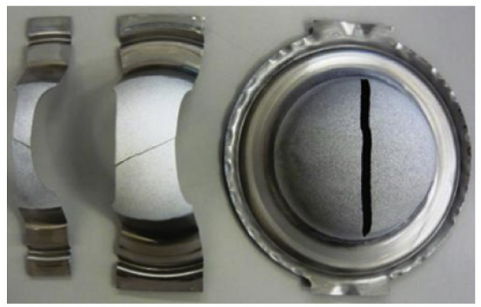

(c)

Fig. 3. (a) Erichsen universal sheet metal testing machine, (b) scheme of the experimental setup and (c) specimen geometries before and after testing. 


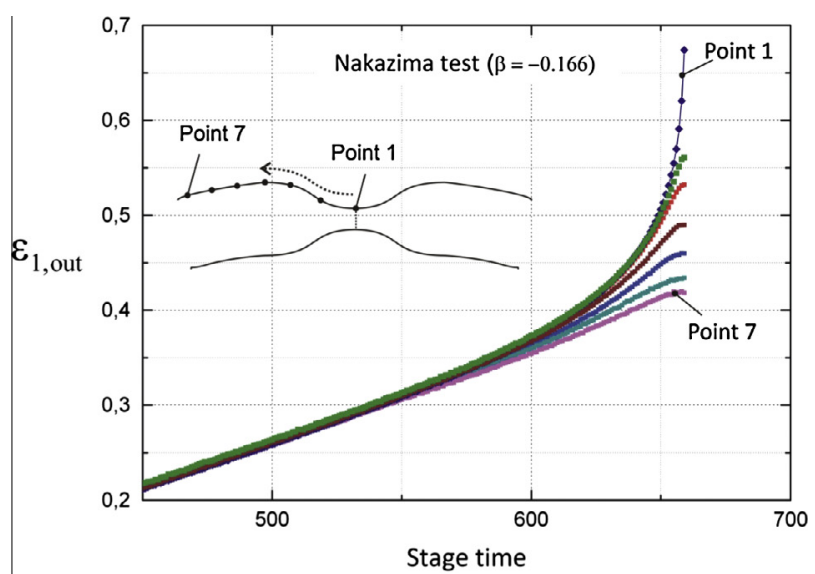

(a)

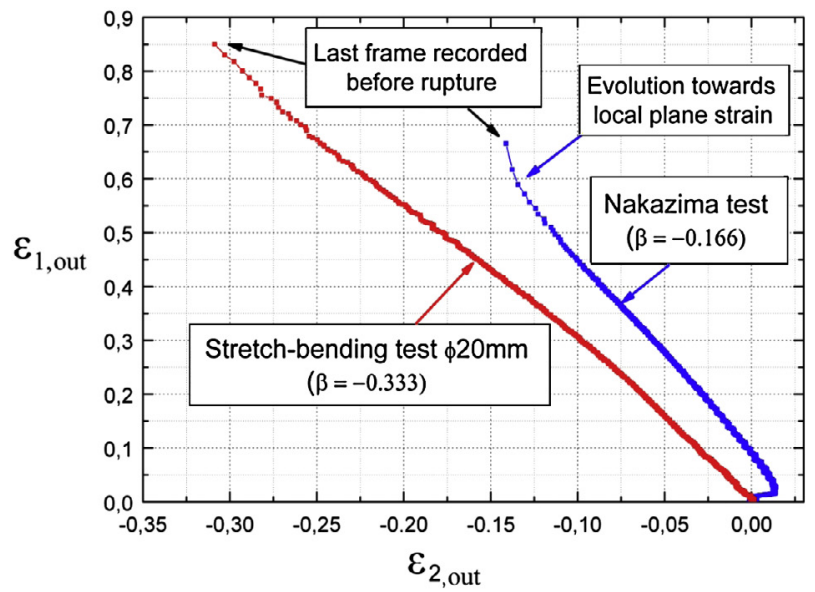

(b)

Fig. 4. Experimental data, (a) time evolution of the major strain for a series of points along a section perpendicular to the failure zone in a Nakazima test and (b) principal strain path in both a Nakazima test and stretch-bending test using $\Phi 20 \mathrm{~mm}$ punch.

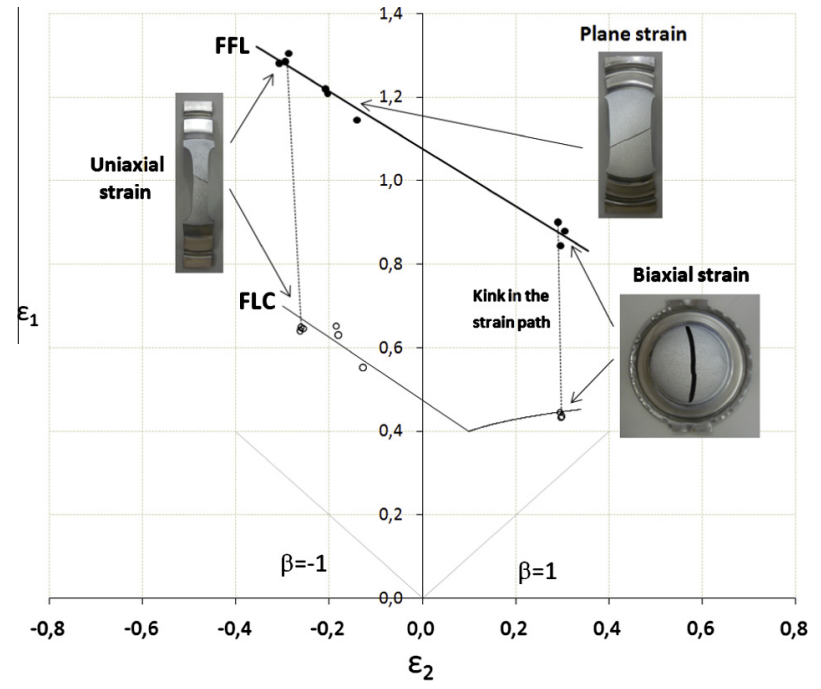

Fig. 5. Forming limit diagram (FLD) based on conventional Nakazima tests containing the forming limit curve (FLC) and the fracture forming line (FFL) for $0.8 \mathrm{~mm}$ thickness AISI 304 metal sheets. for every tested specimen. In addition, some tested specimens were cut perpendicularly to the crack and the thickness was measured from a profile view in order to validate the previous thickness measurements along the crack. The average minor strain was evaluated along the fracture line at the last image recorded by ARAMIS ${ }^{\circledR}$ just before the crack appearance. The major strain was then calculated by volume constancy:

$\bar{\varepsilon}_{1, f}=-\left(\bar{\varepsilon}_{2, f}+\bar{\varepsilon}_{3, f}\right)$

where $\bar{\varepsilon}_{2, f}$ and $\bar{\varepsilon}_{3, f}$ are the average minor and thickness strains evaluated in a series of points along the crack.

The FFL shown in Fig. 5 is approximated by the straight line $\varepsilon_{1}+0.69 \varepsilon_{2}=1.08$ falling to the first quadrant of principal strain with a slope not far from the value of " -1 " as proposed by Atkins in [24]. The transition of the strain path in the first quadrant of the principal strains space is almost vertical from the FLC towards the FFL, while the same transition in the second quadrant suffers from a slight leftward slope, according again to the cited work of Atkins.

\subsection{Stretch-bending tests}

The experimental setup in these experiments was analogous to the previous one, but using cylindrical punches of $\$ 20$ and $\Phi 10 \mathrm{~mm}$. These tests exhibited strain conditions between plane and uniaxial strain. In these cases, a significant through-thickness strain gradient was induced due to the bending introduced by the curvature of the punches.

In these tests, analysed using our DIC setup, the strain evolution of several points, located close and also far from the fracture initiation site, increased monotonically until fracture occurred without showing a priori an unstable strain localisation process in a narrow band. In addition, the development of a local plane strain condition in the last stages at the most strained point in the failure zone was not clearly exhibited for any specimen tested using cylindrical punches (see Fig. 4b for a $\Phi 20 \mathrm{~mm}$ punch). However, a more detailed analysis of the failure region by microscope reveals an incipient necking prior to fracture (see the fractographies for $\Phi 20$ and $\Phi 10 \mathrm{~mm}$ shown in Fig. 6), pointing out that the failure process occurred in a very short time, not being possible to register this initiation of necking using our DIC setup even at maximum frame recording rate ( 12 frames per second). Indeed these fractographies were studied cutting the tested sheet just in the place where the failure initiated, being detected this locations by using the images recorded by the DIC device. This is important, because what happened at this specific location would determine the mechanism controlling failure.

\subsection{Single point incremental forming tests}

The SPIF tests were carried out on a Kondia ${ }^{\circledR}$ HS1000 3-axis milling machine equipped with a Fidia numerical control by using the experimental setup described in [17] and shown in Fig. 1. The testing geometry utilized within the SPIF experimental plan was a conical frustum with circular generatrix, with the initial diameter of the truncated cone set to $70 \mathrm{~mm}$, being the initial drawing angle $20^{\circ}$ and the generatrix radius $40 \mathrm{~mm}$, as can be seen in Fig. 7. The step down was alternatively set to $0.2 \mathrm{~mm}$ and $0.5 \mathrm{~mm}$ per pass, while tool diameters of 20,10 and $6 \mathrm{~mm}$ were used. The rotation of the tool was free. Special lubricant Houghton TD-52 for metal forming applications was used in order to minimize friction effects. The final depth, proportional to the final forming angle, was recorded just in the instant in which the failure took place. Three replicates of each SPIF test were carried out. Table 2 shows the final depth and forming angle for the series of SPIF tests. As can be observed, almost the same final depths, and consequently final forming angles, were repetitive achieved for each case. 

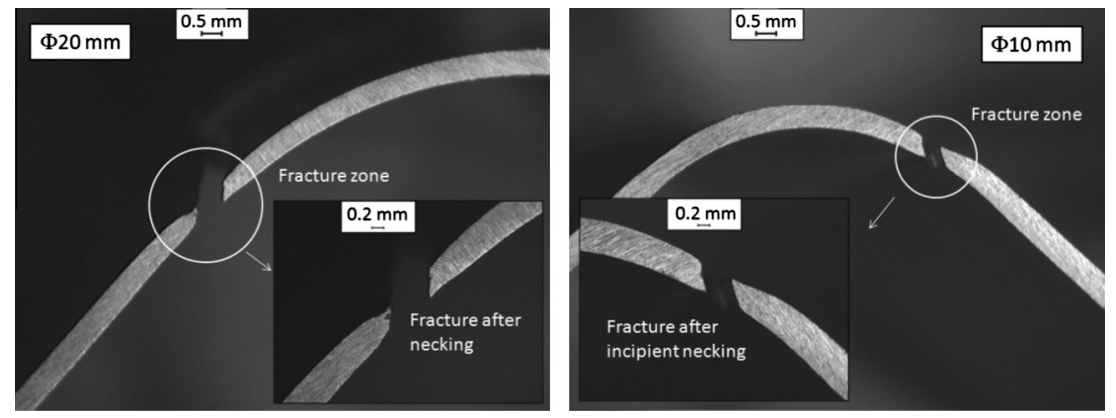

Fig. 6. Fractography of the failure zone in stretch-bending using a cylindrical punch of $\Phi 20$ (left) and $\Phi 10 \mathrm{~mm}$ (right) respectively.

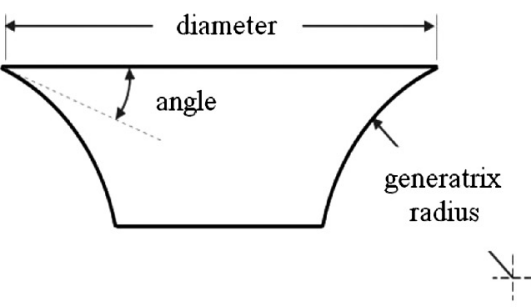

(a)

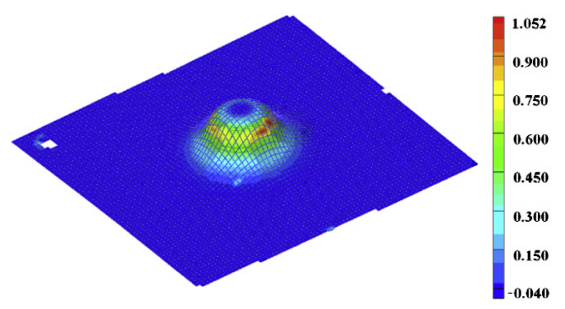

(c)

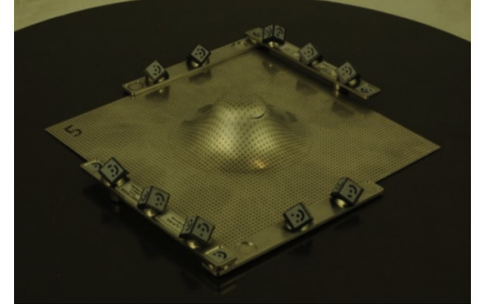

(b)

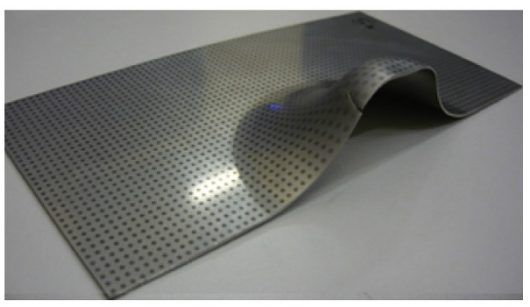

(d)

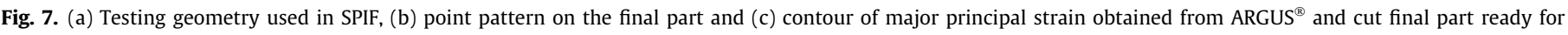
measuring thickness along the crack.

Table 2

Series of SPIF tests carried out

\begin{tabular}{llll}
\hline $\begin{array}{l}\text { Tool diameter } D_{\mathrm{T}} \\
(\mathrm{mm})\end{array}$ & $\begin{array}{l}\text { Step down } \Delta Z \\
(\mathrm{~mm} / \text { pass })\end{array}$ & $\begin{array}{l}\text { Final depth } Z_{\mathrm{f}} \\
(\mathrm{mm})\end{array}$ & $\begin{array}{l}\text { Final forming } \\
\text { angle } \alpha_{\mathrm{f}}\left(^{\circ}\right)\end{array}$ \\
\hline 20 & 0.2 & $23.8 / 23.8 / 23.8$ & $69.8 / 69.8 / 69.8$ \\
20 & 0.5 & $24.5 / 24.0 / 24.0$ & $70.9 / 70.1 / 70.1$ \\
10 & 0.2 & $28.0 / 28.2 / 28.2$ & $76.1 / 76.4 / 76.4$ \\
10 & 0.5 & $27.5 / 28.0 / 28.0$ & $75.4 / 76.1 / 76.1$ \\
6 & 0.2 & $28.2 / 28.0 / 28.8$ & $76.4 / 76.1 / 77.3$ \\
6 & 0.5 & $28.0 / 28.5 / 28.0$ & $76.1 / 76.9 / 76.1$ \\
\hline
\end{tabular}

Contrary to stretching and stretch-bending tests in which the strain paths were measured on-line, in the case of SPIF the strain state was measured off-line on the final part in the light of circle grid analysis by using the 3D deformation digital measurement system ARGUS ${ }^{\circledR}$. Previous to test, a point pattern of $1 \mathrm{~mm}$ diameter had to be created on the sheet blank by an electrolytic etching process. Fig. $6 \mathrm{~b}$ depicts the point pattern after deforming a metal sheet by SPIF until failure with a hemispherical forming tool of $20 \mathrm{~mm}$ diameter. The analysis of the tested sheet performed using ARGUS ${ }^{\circledR}$ provided the contour of principal strains on the outer surface of the final part (see Fig. 7c). As expected, the area of maximum major strain was located at the vicinity of the crack (notice that orientation of the final part coincides in Figs. 7b and c). In fact, the measurement system was able to capture the deformation of the ellipses both above and below the crack, and therefore able to interpolate the strains throughout it. The fracture strains for SPIF tests were obtained measuring the sheet thickness along the crack at both sides of the final cut (see Fig. 7d) following the same methodology based on volume constancy explained in Section 2.1.

A table-type dynamometer Kistler ${ }^{\circledR}$ 9257B was mounted in the machine-table in order to measure the forming forces that occur during the SPIF process. The forces were acquired using a DaqBoard 505 data acquisition card and the DaqView 9.0.0 software, focusing the analysis on the maximum forming force in the vertical direction $F_{z, \max }$. The forming forces were registered with a frequency of $10 \mathrm{~Hz}$ using the dynamometric table. Then, its magnitudes were filtered using Matlab ${ }^{\circledR}$ to obtain its maximum value.

\section{Results and discussion}

In the first part of this section, the results obtained in SPIF are analysed within the FLD of the material, taking into account the tool diameter and the step down. The second part focuses on the comparative analysis of stretch-bending vs. SPIF for equal values of tool diameter. These results are used to discuss the influence of the bending effect in the formability of SPIF parts. Finally, the forming force is analyzed by introducing a new process parameter in the study, the angular velocity of the forming tool.

\subsection{Spifability}

From the direct experimental results showed in Table 2, two facts can be remarked: (1) the final depths, and consequently the 
final forming angles, are repetitive for each case; and (2) it can be noticed that, as expected, formability in SPIF increased as the tool diameter decreased. However, a saturation of the enhancement of formability appeared in the tests corresponding to $6 \mathrm{~mm}$ diameter of tool diameter. This saturation is produced by the indentation of this forming tool in the inner suffer of the metal sheet, shaving off material and therefore counteracting the likely beneficial effect due to the increase of localized bending. In this context, the cases that would provide the limits of spifability are those corresponding to 10 and $20 \mathrm{~mm}$ of tool diameter. Hereafter the spifability is characterised by the maximum strain level attained at the outer surface of the metal sheet before fracture.

The experimental results included in Fig. 8 show the spifability of the AISI 304 metal sheets for these diameters of 10 and $20 \mathrm{~mm}$, in each case for the step downs of 0.2 and $0.5 \mathrm{~mm}$ per pass considered. Already in the case of $20 \mathrm{~mm}$ diameter the enhancement of formability is important enough to allow stable plastic deformation until values of major principal strain over 0.9 , well above the FLC and not far from the FFL fracture line. In fact, in the case of a forming tool of $10 \mathrm{~mm}$ diameter, the enhancement of formability makes the principal strains to reach the FFL within stable deformation. As can be seen, the major principal strain reach values up to 1.1 of logarithmic strain placed nearly above the FFL determined in Nakazima tests. In addition, decreasing the step down from 0.5 to $0.2 \mathrm{~mm}$ per pass caused just a slightly beneficial effect in spifability. This seems to be due the more progressive deformation imposed to the sheet as decreasing the step down.

The fracture zone has been analysed at microscope in both tests, i.e. for tool diameters of $\Phi 20$ and $\Phi 10 \mathrm{~mm}$. Besides the expected reduction of thickness due to the incremental deformation process, a distinctive necking has been appreciated at the fracture zone, especially for the case of $\Phi 20$. Fig. 9 shows a fractography for the tests of tool diameters of $\Phi 20$ (top) and $\Phi 10 \mathrm{~mm}$ (bottom) respectively, showing in both cases the crack zone (left) and the opposite side (right). According to this figure it can be concluded that the mechanism of failure for the tests of $\Phi 20 \mathrm{~mm}$ has been a postponed necking followed by ductile fracture, as pointed out in similar studies for these relative low values of the $t_{0} / R$ ratio $[2,22,23]$. On the other hand, in the case of $\Phi 10 \mathrm{~mm}$, the outer sheet surface shows a series of grooves, which are related to an incipient necking, as it was discussed by other authors, see for instance the work of Wilson et al. [26,27]. This behaviour is in agreement with the previously observed in Fig. 6 for stretch-bending tests, demonstrating

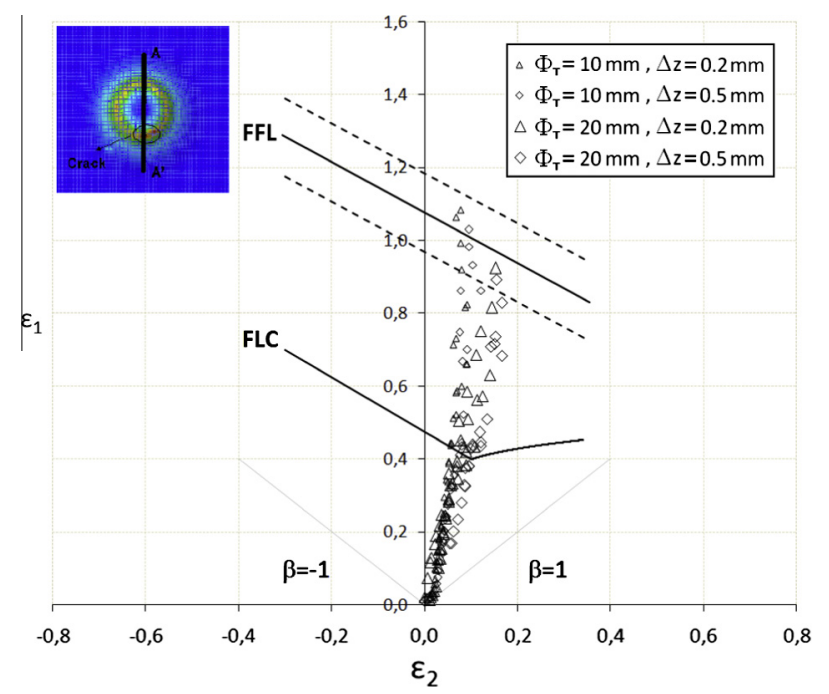

Fig. 8. Spifability of the AISI 304 metal sheets using tool diameters of 10 and $20 \mathrm{~mm}$ for step downs of 0.2 and $0.5 \mathrm{~mm}$ per pass. that the failure mode activated in both forming processes, i.e. stretch-bending and SPIF is directly linked to the $t_{0} / R$ ratio. That is, for a specific value of this ratio, the same failure mode would occur for the two processes analysed.

On the other hand, smaller tool diameters, as it is the case of $10 \mathrm{~mm}$ diameter, concentrate deformation at the small zone of the sheet placed under the forming tool at any moment, whereas larger tools, for instance of $20 \mathrm{~mm}$ diameter, tend to distribute the strains over a more extended area. This makes the minor strain remaining closer to plane strain conditions for the case of the tool of $10 \mathrm{~mm}$ diameter, while for the case of the tool of $20 \mathrm{~mm}$ diameter the strain distribution along the wall of the part formed by SPIF present a slightly deviation towards biaxial conditions, as can be seen in Fig. 9 .

\subsection{Stretch-bending vs. SPIF}

In this section the strain evolutions of stretch-bending tests carried out for cylindrical punches of 20 and $10 \mathrm{~mm}$ diameter are analyzed versus the final strains distribution of truncated cones with variable angle deformed by SPIF, also for tool diameters of 20 and $10 \mathrm{~mm}$ respectively. These results are shown in Fig. 10 separately for each tool diameter, allowing comparing situations with the same tool radius. In spite of the strain paths for stretch-bending and SPIF tests are not the same, some interesting conclusions regarding the effective influence of bending can be drawn.

The results in the case of tool diameter of $20 \mathrm{~mm}$ (see Fig. $10 \mathrm{a}$ ) show that, although in SPIF stable plastic deformation well above the FLC is achieved, stretch-bending tests initiate failure by necking for a level of strains just slightly above the FLC. As this necking in stretch-bending was not detected by our DIC system, the necking strains were directly measured by microscope (average necking strains represented by cross-shaped marks in Fig. 10) using the sheet thickness just delimiting the unstable region, as shown in the schema placed up-leftwards in Fig. 10. On the other hand, the procedure for obtaining fracture strains is based on the measure of thicknesses at several places along the crack in order to obtain an average thickness strain and calculate the pair major/ minor strain at fracture. An evolution from necking to fracture via local plane strain conditions was assumed (dotted vertical lines in Fig. 10). Moreover, in this case in which a similar bending effect is attained due to the same tool diameter, it can be seen that the enhancement of formability above the FLC in SPIF is much higher than in stretch-bending. In fact, the parameter $\Delta$, defined as the percentage enhancement of formability over the FLC (represented in Fig. 10a for stretch-bending and SPIF), reaches values around $30 \%$ in stretch-bending $\left(\Delta_{\text {S-B }}\right)$ while in SPIF $\left(\Delta_{\text {SPIF }}\right)$ values slightly above $100 \%$ are reached.

On the other hand, for the tool of $10 \mathrm{~mm}$ diameter (see Fig. 10b), failure in stretch-bending tests occurs by an incipient necking prior to fracture for a level of strains a quite above the FLC, while in SPIF even higher values are observed than for the $20 \mathrm{~mm}$ diameter tool. Again, the increase of formability in SPIF is much higher than in stretch-bending. Values of $\Delta_{\mathrm{S}-\mathrm{B}}$ around $30 \%$ are also obtained and values of $\Delta_{\text {SPIF }}$ up to $150 \%$.

According to these results, it seems reasonable that the local bending induced by the punch radius, although it plays an important role, is not the only parameter permitting a high stable deformation above the FLC in SPIF. In the authors view, the local and incremental character of the deformation and the bending effect are the two main factors controlling the formability in SPIF. The former induces a small and moving deformation zone, so any plastic instability is likely to have neither time nor space to initiate or to develop properly. The latter promotes a local strain gradient through the sheet thickness, delaying the development of necking or even suppressing its formation. Other factors that also may help 

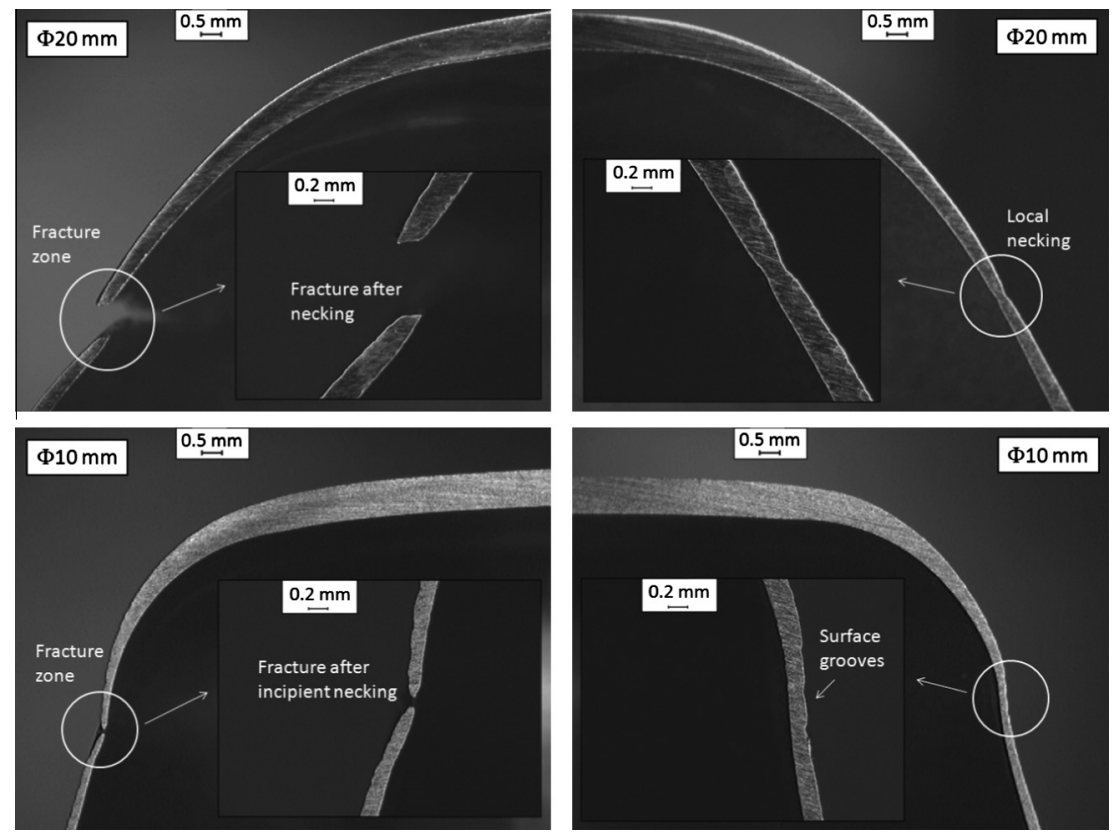

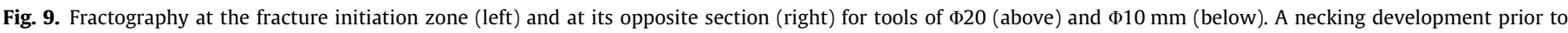
fracture appearance is observed.

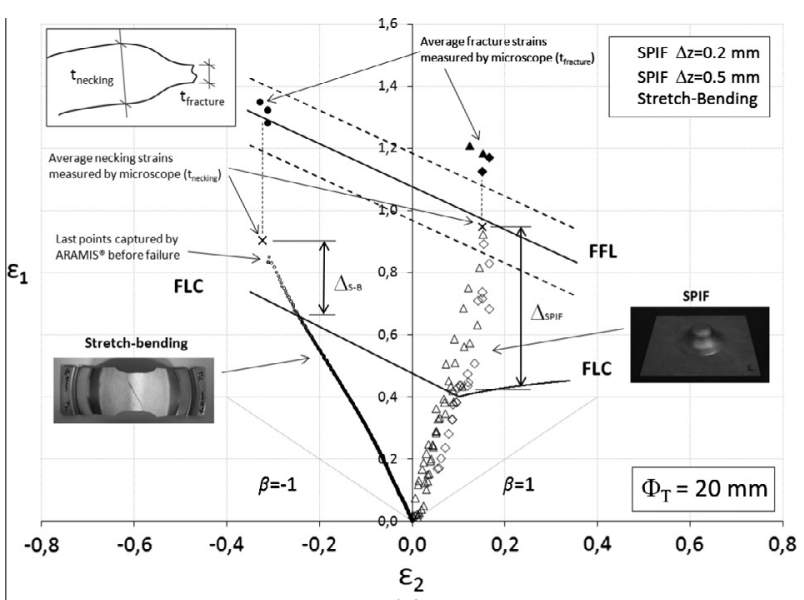

(a)

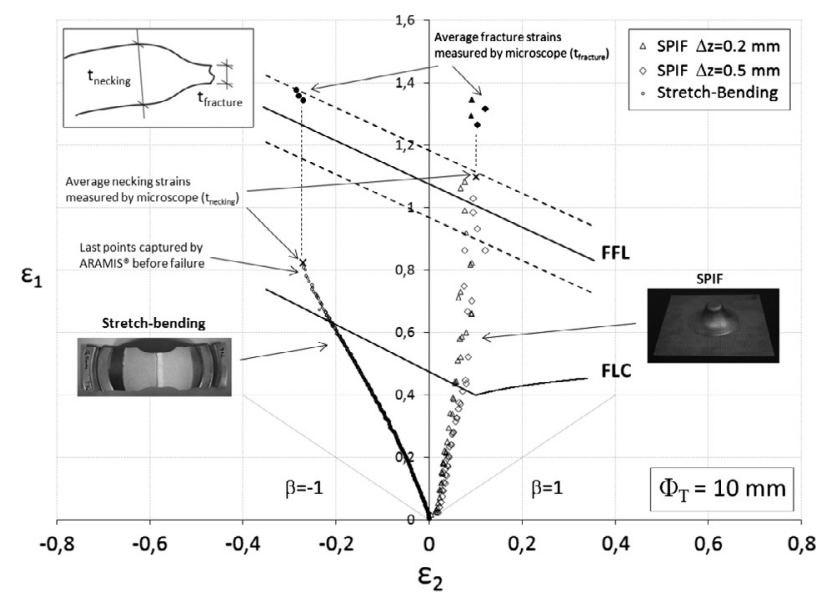

(b)

Fig. 10. Formability until fracture in SPIF vs. Stretch-bending using tool diameters of (a) $20 \mathrm{~mm}$ and (b) $10 \mathrm{~mm}$ respectively. to the enhancement of the formability in SPIF are the triaxiality ratio, the shear stress, the contact pressure and the cyclic straining [3].

As it was discussed above, in stretch-bending and SPIF tests the failure is governed by necking or fracture depending on the $t_{0} / R$ ratio. In particular, for the tool diameters considered here necking seems to be the failure mechanism, especially for the higher tool diameter of $20 \mathrm{~mm}$ corresponding to a lower $t_{0} / R$ ratio. However, for this material, a clear trend towards failure by ductile fracture in the absence of necking does not appear, contrary to what is observed in some aluminium alloys deformed by SPIF for high $t_{0} / R$ ratios $[2,21-23]$.

On the other hand, the fracture strains are evaluated within the scatter band of $\pm 10 \%$ with respect to the experimental FFL, as it was done in other studies on formability such as [2]. Meanwhile the fracture strains in stretch-bending are placed within the cited scatter band, in SPIF the fracture strains are located above it, especially in the case of $\Phi 10 \mathrm{~mm}$ tool. This experimental fact can be also seen in [2], and would imply that, for some materials, Nakazima tests might not be suitable to evaluate the FFL. In this regard, it is well known that the level of triaxiality in stretching tests (e.g. Nakazima) is much higher than in SPIF tests $[2,4]$. So, the ability to match the fracture limit strain in SPIF and Nakazima tests will depend on the sensitivity of the material to the triaxiality state for fracture. In addition, Fig. 10(a) and (b) depicts that fracture strains in stretchbending and SPIF tests reach almost the same level of major strain for a given tool diameter. This is not surprising as far as the level of triaxiality in both types of tests is expected to be similar [21].

Finally, it must be said that recent studies [28,29] use the so called percentage necking strain, as defined in Eq. (3), to quantify the unstable deformation range from the onset of necking until fracture, for different strain paths.

Percentage necking $=\frac{\varepsilon_{1, \text { fracture }}-\varepsilon_{1, \text { necking }}}{\varepsilon_{1, \text { necking }}}$

Regarding the conventional FLD for the selected material depicted in Fig. 5, it can be observed that this percentage of necking strain for Nakazima tests exhibits an average value around $110 \%$ for any strain path, due to the parallelism of experimental 
FLC and FFL. Specifically, for uniaxial tension, plane strain and biaxial tension, these values are $100 \%, 125 \%$ and $110 \%$ respectively. This result revels the size of the unstable deformation zone observed in conventional forming processes, which can be substantially increased using especial processing techniques, e.g. cryorolling $[28,29]$.

However, the percentage of necking strain decreases slightly for the stretch-bending tests, showing values down to $75 \%$, due to the influence of bending in postponing necking as discussed before. This trend is also observed in the SPIF tests, where the mechanisms delaying or even suppressing the necking are even more actives. As can be seen, lower percentage necking strains are attained in these cases, reaching values under the $29 \%$ for a $\Phi 20 \mathrm{~mm}$ forming tool and under the $23 \%$ for $\Phi 10 \mathrm{~mm}$. It is expected that this value approaches zero when $t_{0} / R$ ratio decreases, indicating that the failure in SPIF would occur by ductile fracture under an eventual absence of necking.

\subsection{Forming force}

In order to analyze the influence of the axial forming force a series of additional SPIF tests were carried out. As mentioned before, three tool diameters $(6,10$ and $20 \mathrm{~mm})$ and two levels of step down ( 0.2 and $0.5 \mathrm{~mm}$ ) were considered. With the aim of analysing the effect of the spindle speed versus the case of free spindle rotation, a set of tests similar to the series described in Section 2.3 has been carried out using an imposed rotation of $1000 \mathrm{rpm}$. Table 3 shows the final depth and forming angle for this set of SPIF tests with spindle rotation. As happened in Table 2, almost the same final depths and forming angles were repetitive achieved for each case.

Table 4 shows the average maximum axial force recorded during each type of test as a function As can be observed in Table 4 and Fig. 11, the maximum axial force increases as the $t_{0} / R$ ratio decreases. Therefore, for a constant value of sheet thickness, the forming force increases with the tool diameter. This fact is due to a higher contact area between the tool and the blank when higher tool diameters are used. The process time could be reduced with the use of higher tool diameters because higher step downs could be employed without compromising the surface finishing. However, the forming force would increase, which could be a limiting and not desirable factor for the machinery used in the manufactur-

Table 3

Series of additional SPIF tests carried out $(S=1000 \mathrm{rpm})$.

\begin{tabular}{llll}
\hline $\begin{array}{l}\text { Tool diameter } D_{\mathrm{T}} \\
(\mathrm{mm})\end{array}$ & $\begin{array}{l}\text { Step down } \Delta Z \\
(\mathrm{~mm} / \text { pass })\end{array}$ & $\begin{array}{l}\text { Final depth } Z_{\mathrm{f}} \\
(\mathrm{mm})\end{array}$ & $\begin{array}{l}\text { Final forming } \\
\text { angle } \alpha_{\mathrm{f}}\left({ }^{\circ}\right)\end{array}$ \\
\hline 20 & 0.2 & $22.8 / 23.0 / 23.8$ & $68.3 / 68.6 / 68.9$ \\
20 & 0.5 & $24.5 / 24.5 / 24.5$ & $70.9 / 70.9 / 70.9$ \\
10 & 0.2 & $29.2 / 28.6 / 29.0$ & $78.2 / 77.0 / 77.6$ \\
10 & 0.5 & $29.0 / 29.5 / 29.0$ & $77.6 / 78.3 / 77.6$ \\
6 & 0.2 & $28.6 / 28.4 / 28.6$ & $77.0 / 76.7 / 77.0$ \\
6 & 0.5 & $28.5 / 28.5 / 28.5$ & $76.9 / 76.9 / 76.9$ \\
\hline
\end{tabular}

Table 4

Mean values of the maximum forming force $\left(F z_{\max }\right)$ expressed in $\mathrm{kN}$.

\begin{tabular}{|c|c|c|c|c|}
\hline \multirow[t]{3}{*}{ Tool diameter $D_{\mathrm{T}}(\mathrm{mm})$} & \multicolumn{4}{|c|}{ Step down $\Delta Z(\mathrm{~mm} /$ pass $)$} \\
\hline & \multicolumn{2}{|l|}{0.2} & \multicolumn{2}{|l|}{0.5} \\
\hline & $S=$ free & $S=1000 \mathrm{rpm}$ & $S=$ free & $S=1000 \mathrm{rpm}$ \\
\hline 20 & 2.421 & 3.581 & 1.902 & 2.525 \\
\hline 10 & 1.665 & 2.077 & 1.548 & 1.827 \\
\hline 6 & 1.492 & 1.757 & 1.468 & 1.688 \\
\hline
\end{tabular}

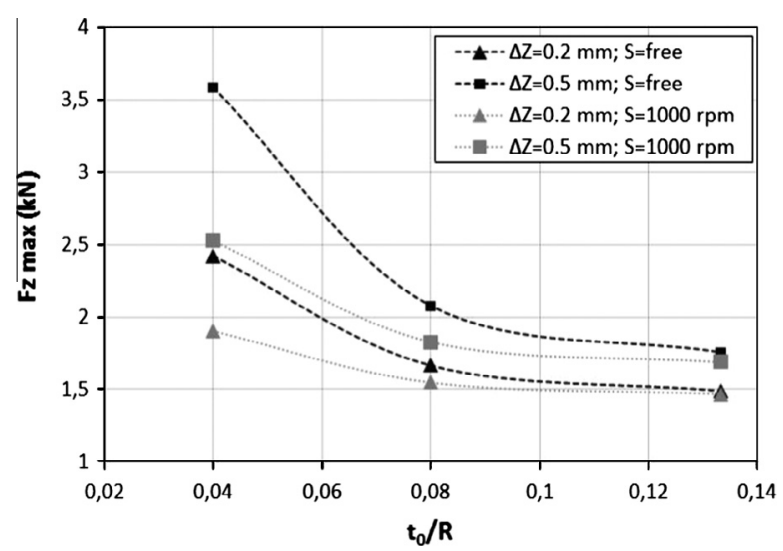

Fig. 11. Evolution of the maximum axial force depending on the $t_{0} / R$ ratio.

ing process [1]. An increase of the step down causes an increase of the maximum force. The main reason is that more material has to be pushed down for major step downs, thus, the local deformation of the sheet is higher.

Other research works have previously identified the effect of the step down and the tool diameter in the forming force $[13,16]$. An empirical equation (Eq. (4)), able to predict the forming forces for UWA components, has been proposed by Aerens et al. [13]. The applicability of Eq. (4) for Variable Wall Angle (VWA) geometries has been validated in previous works of the authors [30,31] for different geometries.

$F z_{z}=0.0716 \cdot R_{m} \cdot t_{0}^{1.57} \cdot d_{t}^{0.41} \cdot \Delta h^{0.09} \cdot \alpha \cdot \cos \alpha$

where $R_{\mathrm{m}}$ is the ultimate tensile strength, $t_{0}$ is the initial sheet thickness, $d_{\mathrm{t}}$ is the tool diameter, $\alpha$ is the initial wall angle and $\Delta h$ is the scallop height, for which [13] proposed the following approximation:

$\Delta z=2 \cdot \sin \alpha \cdot \sqrt{\Delta h \cdot\left(d_{t}-\Delta h\right)} \approx 2 \cdot \sin \alpha \cdot \sqrt{\Delta h \cdot d_{t}}$

However, the effect of the spindle speed is not considered in the equation, although Fig. 11 demonstrates that its effect can be significant, especially for the case of a forming tool of $\Phi 20 \mathrm{~mm}$. As can be seen, the higher spindle speed is, the lower maximum forming force is reached.

Comparing the maximum force of the experiments using a step down of $0.5 \mathrm{~mm}$ and two spindle speeds (free and $1000 \mathrm{rpm}$ ) represented in Fig. 11, it can be seen that there is an important reduction of the force for lower $t_{0} / R$ ratios when the spindle speed is set to $1000 \mathrm{rpm}$. In fact, the maximum force level is approximately the same that the one obtained in the experiments done using a step down of $0.2 \mathrm{~mm}$ and a free tool rotation. This fact is important because this indicates that is possible to increase the productivity (higher step down will lead to less production time) without exceeding the limits of safe utilization of the hardware by simply performing a fine tuning of the spindle speed and the step down of the process.

Previous research works have demonstrated that for higher spindle speeds the forming temperature increases [14]. In the present paper, a thermo-graphic camera has been used in order to register the temperature variation during the forming process. Fig. 12a shows the maximum temperature obtained in a test done at $S=1000 \mathrm{rpm}\left(154.51^{\circ} \mathrm{C}\right)$, while the maximum temperature obtained for a test done using a free tool rotation was $83.20^{\circ} \mathrm{C}$. Thus, an increase of about $70^{\circ} \mathrm{C}$ has been obtained by the spindle rotation due to the heat generated by the friction between the tool and the blank. In this sense Palumbo and Brandizzi [14] pointed out the effect of the tool rotation speed in increasing the forming 


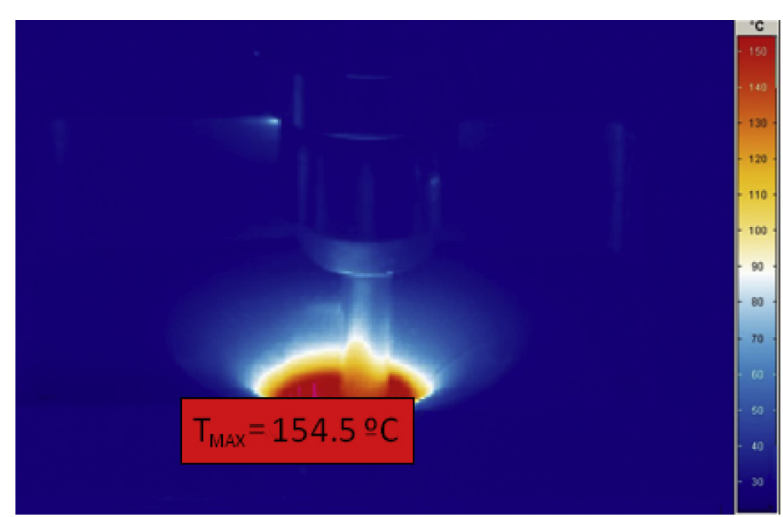

(a)

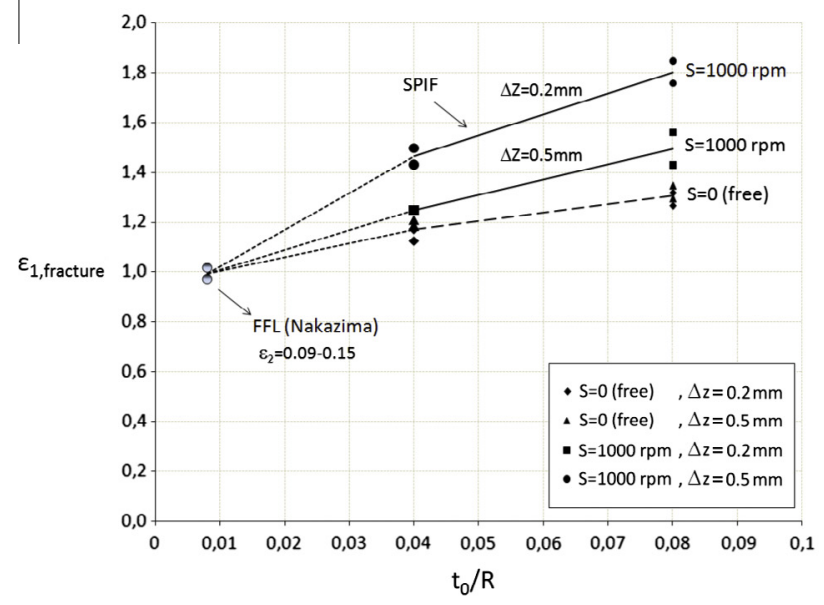

(b)

Fig. 12. (a) Maximum temperature registered for $S=1000 \mathrm{rpm}$ by thermo-graphic camera and (b) fracture strains measured by microscope for $S=0$ (free) and $S=1000 \mathrm{rpm}$.

temperature and in stabilizing the necking, allowing reaching a higher formability. In fact, Ambrogio et al. [32] proposed a novel variant of incremental sheet forming in which a continuous current is supplied in order to generate a local heating to allow a higher formability and lower forces in manufacturing of lightweight alloys.

Henrard et al. [15] and Eyckens et al. [16] have concluded that the forming forces depend notably on the Through-Thickness Shear (TTS) in the sheet induced by the sliding contact with friction between the sheet and the forming tool, which clearly increases with the spindle speed. Thus, it seems that the combination of the increasing temperature and specially the shear stresses generated when the spindle speed increases must be taken into account to explain the reduction of the forming force and the increase of formability observed in these experimental tests. Moreover, Eyckens et al. claimed in [16] the spindle does not affect especially that vertical forming force, decreasing though sensibly the forming forces in the plane perpendicular to the forming tool axis. Although this is true for the small tool diameters usually used in SPIF, for higher tool diameters such as $\Phi 20 \mathrm{~mm}$, there is experimental evidence that the spindle rotation considered decreased the vertical forming force (see Fig. 11).

Fig. 12b shows the major strain at fracture versus the $t_{0} / R$ ratio for SPIF tests with free spindle speed and $S=1000 \mathrm{rpm}$. Fracture strains corresponding to the FFL (obtained from Nakazima tests) are included in Fig. 11b as a reference. As can be observed, the fracture strain in the case of $S=1000 \mathrm{rpm}$ is notably higher than the one obtained at a free spindle speed, for both tool diameters of
10 and $20 \mathrm{~mm}$. Moreover, the influence of the step down, which was almost negligible in the case of free rotation, has a considerable influence in the case of $S=1000 \mathrm{rpm}$. In this case, the lower step down provided higher values of major strain at fracture. According to these results, a clear increase of formability in SPIF is obtained by either increasing the tool rotation or decreasing the step down.

It should be mentioned that the maximum temperature registered of about $154{ }^{\circ} \mathrm{C}$ is obviously not enough to provide a significantly variation of the mechanical properties of the metal sheets of AISI 304, as SPIF process remains in cold forming.

\section{Conclusions}

This paper analysed experimentally the spifability of AISI 304 metal sheets in the light of circle grid analysis. The characterization of formability limits in conventional Nakazima tests is performed and compared with stretch-bending and SPIF in order to determine the influence of bending in the limit strains. The failure mode observed was postponed necking followed by ductile fracture.

Comparing the influence of bending in SPIF and stretch-bending, it was observed that the enhancement of formability above the FLC in SPIF is much higher than in stretch-bending. In fact, the percentage enhancement of formability remains around 30\% in stretch-bending for the two diameters analysed. On the contrary, the enhancement of spifability increased as the tool diameter decreased up to values around $150 \%$ for the case of the lower tool diameters. Thus, it can be pointed out that, although the bending effect induced by the punch radius plays an important role in SPIF, this is not the unique factor allowing stable deformations well above the FLC.

On the other hand, it was noticed that fracture strains in stretch-bending were placed close to the FFL obtained from Nakazima tests, while in SPIF the fracture strains were located above it, especially in the case of the lower tool diameter. This effect could have a high material dependence, so this phenomenon should be analysed for other materials.

Regarding the forming force, it can be concluded that by controlling the spindle speed, a wider range of materials can be employed in SPIF processes: from very ductile (such as soft aluminum alloys) to low ductility materials without compromising the safe utilization of the process equipment. In this regard, within the range of forming parameters corresponding to small $t_{0} / R$ ratios, the spindle rotation plays an important role decreasing the vertical forming force, variable that usually compromises the integrity of non-dedicated SPIF machinery.

\section{Acknowledgments}

The authors wish to thank the Spanish Government for its financial support through the research project DPI2012-32913 and DPI2012-36042. The work of M.Sc. Carlos Suntaxi within this investigation is also greatly acknowledged. The second author would also like to thank the support of the Spanish scholarship FPU12/05402.

\section{References}

[1] Jeswiet J, Micari F, Hirt G, Bramley A, Duflou J, Allwood J. Asymmetric single point incremental forming of sheet metal. Ann CIRP 2005;54:623-50.

[2] Silva MB, Nielsen PS, Bay N, Martins PAF. Failure mechanisms in single point incremental forming of metals. Int J Adv Manuf Technol 2011;56:893-903.

[3] Emmens WC, Van den Boogaard AH. An overview of stabilizing deformation mechanisms in incremental sheet forming. J Mater Process Technol 2009;209:3688-95.

[4] Centeno G, Doblas FJ, Martínez-Palmeth LH, Martínez-Donaire AJ, Vallellano C. FEA of the bending effect in the formability of metal sheets via incrementa 
forming. In: Proc. metal forming international conference. Kraków, Poland; 2012. p. 447-50.

[5] Allwood JM, Shouler DR. Generalised forming limit diagrams showing increased forming limits with non-planar stress states. Int J Plast 2009;25:1207-30.

[6] Jackson K, Allwood JM. The mechanics of incremental sheet forming. J Mater Process Technol 2009;29:1158-74

[7] Eyckens P, Van Bael A, Van Houtte P. Marciniak-Kuczynski type modelling of the effect of through-thickness shear on the forming limits of sheet metal. Int J Plast 2009;25:2249-68.

[8] Eyckens P, Van Bael A, Van Houtte P. An extended Marciniak-Kuczynski model for anisotropic sheet subjected to monotonic strain paths with throughthickness shear. Int J Plast 2011;27:1577-97.

[9] Emmens WC, Van den Boogaard AH. Cyclic stretch-bending: mechanics, stability and formability. J Mater Process Technol 2011;211:1965-81.

[10] Vallellano C, Morales-Palma D, Martínez-Donaire AJ, García-Lomas FJ. On the use of concave-side rule and critical-distance methods to predict the influence of bending on sheet-metal formability. Int J Mater Form 2010;3:1167-70.

[11] Morales-Palma D, Vallellano C, García-Lomas FJ. Assessment of the effect of the through-thickness strain/stress gradient on the formability of stretch-bend metal sheets. Mater Des 2013;50:798-809.

[12] Stoughton TB, Yoon JW. A new approach for failure criterion for sheet metals. Int J Plast 2011;27:440-59.

[13] Aerens R, Eyckens P, Van Bael A, Duflou JR. Force prediction for single point incremental forming deduced from experimental and FEM observations. Int J Adv Manuf Technol 2010;46:969-82.

[14] Palumbo G, Brandizzi M. Experimental investigations on the single point incremental forming of a titanium alloy component combining static heating with high tool rotation speed. Mater Des 2012;40:43-51.

[15] Eyckens P, Duflou J, Van Bael A, Van Houtte P. The significance of friction in the single point incremental forming process. IntJ Mater Form 2010;3(S1):947-50.

[16] Henrard C, Bouffioux C, Eyckens P, Sol H, Duflou J, Van Houtte P, et al. Forming forces in single point incremental forming: prediction by finite element simulations, validation and sensitivity. Comput Mech 2011;47:573-90.

[17] Perez-Santiago R, Bagudanch I, García-Romeu ML, Hendrichs N. Effect of strain hardening exponent in the incremental sheet forming force. In: Proc. metal forming international conference. Kraków, Poland; 2012. p. 439-42.

[18] International Standard ISO 12004-2:2008. Metallic materials-sheet and stripdetermination of forming limit curves, Part 2: Determination of forming limit curves in the laboratory. International Organisation for Standardization, Geneva, Switzerland; 2008.
[19] Martínez-Donaire AJ, Vallellano C, Morales-Palma D, García-Lomas FJ. Experimental detection of necking in stretch-bending conditions: a critical review and new methodology. Steel Res Int 2010;81:781-4.

[20] Martínez-Donaire AJ, García-Lomas FJ, Vallellano C. New approaches to detect the onset of localised necking in sheets under through-thickness strain gradients. Mater Des 2014;57:135-45.

[21] Silva MB, Skjoedt M, Atkins AG, Bay N, Martins PAF. Single-point incremental forming and formability-failure diagrams. I Strain Anal Eng Des 2008:43:15-35.

[22] Silva MB, Skjoedt M, Bay N, Martins PAF. Revisiting single-point incremental forming and formability/failure diagrams by means of finite elements and experimentation. J Strain Anal Eng Des 2009;44(4):221-34.

[23] Centeno G, Silva MB, Cristino VAM, Vallellano C, Martins PAF. Hole-flanging by incremental sheet forming. Int J Mach Tools Manuf 2012;59:46-54.

[24] Atkins AG. Fracture mechanics and metal forming: damage mechanics and the local approach of yesterday and today. In: Fracture research in retrospect, Rossmanith HP, editor, A.A. Balkema, Rotterdam; 1997. p. 327-50.

[25] Atkins AG. Fracture in forming. J Mater Process Technol 1996;56:609-18.

[26] Wilson DV, Roberts WT, Rodrigues PMB. Effect of grain anisotropy on limit strains in biaxial stretching: Part I. Influence of sheet thickness and grain size in weakly textured sheets. Metall Trans A 1981;12(9):1595-602.

[27] Wilson DV, Mirshams AR, Roberts WT. An experimental study of the effect of sheet thickness and grain size on limit-strains in biaxial stretching. Int J Mech Sci 1983;25(12):859-70.

[28] Chandra Sekhara K, Narayanasamya R, Venkateswarlub K. Experimental investigations on microstructure and formability of cryorolled AA 5052 sheets. Mater Des 2014;53:1064-70.

[29] Chandra Sekhara K, Narayanasamya R, Venkateswarlub K. Formability, fracture and void coalescence analysis of a cryorolled $\mathrm{Al}-\mathrm{Mg}-\mathrm{Si}$ alloy. Mater Des 2014;57:351-9.

[30] Perez-Santiago R, Bagudanch I, Garcia-Romeu ML. Force modelling in single point incremental forming of variable wall angle components. Key Eng Mater 2011:473:833-40.

[31] Bagudanch I, Perez-Santiago R, Garcia-Romeu ML, Rodríguez C. Forming force in SPIF of variable wall angle components: FEM modeling and experimental results, In: Proc. international conference of technology of plasticity; 2011. p. 541-6.

[32] Ambrogio G, Filice L, Gagliardi F. Formability of lightweight alloys by hot incremental sheet forming. Mater Des 2012;34:501-8. 